\title{
Response-letter to the editor regarding nutrient density of beverages in relation to climate impact
}

Dear Editor,

We thank Drs. Scarborough and Rayner for their comments regarding our recent paper on nutrient density of beverages in relation to climate impact (1). We hope that they do not disagree with the central premise of our research: that calculations of greenhouse gas emissions from the food system ought to take nutrient density of foods or beverages into account. The desirable food products are those that are sustainable but also have maximum nutritional value.

On the more technical side, Drs. Scarborough and Rayner express concerns about the precise thresholds used to illustrate the point above. One challenge in designing a nutrient profile is to make sure that foods or beverages that contain a large amount of a single nutrient do not get a disproportionately high score. A good profiling model needs to take into account both nutrient amount and nutrient balance.

Diverse methods have been used in the past. In 1974, the Federal Trade Commission (FTC) proposed limiting the use of the term 'nutritious' to foods that provided $>10 \%$ of the US recommended dietary allowances (RDA) for protein and three other nutrients per 100 $\mathrm{kCal}$ (2). One suggestion was that 'nutritious' foods ought to provide $50 \%$ of the RDA for one nutrient, $20 \%$ for two nutrients, $15 \%$ for three nutrients, $10 \%$ for four nutrients, and $6 \%$ for five nutrients per reference amount. Along similar lines, Padberg et al. (3) later proposed a point score where products containing $20 \%$ daily values (DV) per serving were assigned 100 points, whereas those containing $14-16 \%$ DV got 50 points, and those containing $10-13 \%$ DV only got 25 points. In such a system, lower DVs of multiple nutrients $(>4)$ were still worth more than $20 \%$ DV of only one nutrient.

The present attempt to incorporate the notion of nutrient diversity into the model is based on such considerations, and is probably closer to the model of Padberg than to the later models of Guthrie (4) and Drewnowski (5). Drewnowski's models set a $100 \%$ maximum for all percentages of DV in order to avoid overly high scores.

It should also be mentioned that $10 \%$ DV has long been used by regulatory agencies as the threshold for defining the 'healthfulness' of foods. However, relatively few unfortified foods contain $>10 \%$ DV of multiple nutrients and virtually none contain $>20 \%$. The threshold was, therefore, relaxed to include nutrients with amounts providing at least 5\% DV in the NCDI index. We regret that Drs. Scarborough and Rayner got the impression that the choice was arbitrary - it was not.

Annika Smedman

Unit for Clinical Nutrition and Metabolism Department of Public Health and Caring Sciences Uppsala University, Uppsala, Sweden Department of Research and Development Swedish Dairy Association, Sweden Email: annika.smedman@svenskmjolk.se

Helena Lindmark Månsson Department of Food Technology, Engineering and

Nutrition

Lund University

Lund, Sweden

Department of Research and Development Swedish Dairy Association

Sweden

Adam Drewnowski Center for Public Health Nutrition and the Nutritional

Sciences Program School of Public Health University of Washington

Seattle, WA, USA

Anna-Karin Modin Edman

Department of Research and Development Swedish Dairy Association

Sweden

\section{References}

1. Smedman A, Lindmark-Månsson H, Drewnowski A, Modin Edman AK. Nutrient density of beverages in relation to climate impact. Food Nutr Res 2010; 54: 5170. - DOI: 10.3402/fnr.v54i0. 5170

2. US Federal Trade Commission (1974): Available from: http:// www.ftc.gov [cited 1 October 2010]. 
3. Padberg D, Kubena K, Ozuna T, Kim H, Osborn L. (1993). The nutritional quality index: an instrument for communicating nutrition information to consumers. AFPC Policy Research Report 93-10. College Station, TX: Texas A\&M University.
4. Guthrie HA. Concept of a nutritious food. J Am Diet Assoc 1977; 71: 14-8.

5. Drewnowski A. Concept of a nutritious food: toward a nutrient density score. Am J Clin Nutr 2005; 82: 721-32. 